\title{
Two-stage Stochastic Model for Petroleum Supply Chain from the Perspective of Carbon Emission
}

\author{
He Liqiang* \\ School of Management, Shanghai University \\ Shanghai, China \\ E-mail: 13284933497@qq.com \\ * Corresponding Author
}

\author{
Wang Guoxin ${ }^{1,2}$ \\ 1. School of Management, Shanghai University \\ 2. School of Mathematics and Physics, Nanyang \\ Institute of Technology \\ Shanghai, China \\ Email:yu xinwang617@126.com
}

\begin{abstract}
With the strengthening of environmental protection awareness, carbon emission has become an important factor in the study of petroleum supply chain. This paper studies the petroleum supply chain from the view of carbon emission by combining with the choice of facilities location selection, production, transportation arrangement, and carbon tax policy. Researchers divide the source of crude oil into domestic crude oil and imported crude oil, and also establish a two-stage stochastic model, which is based on the volatility of the price of imported crude oil. Preliminary numerical result reveals that with the emphasis on the carbon factor, the petroleum supply chain prefers to pipeline transportation and imported crude oil, so that the carbon emissions may be controlled effectively.
\end{abstract}

Keywords- Petroleum Supply Chain; Carbon Tax Policy; Stochastic Model; transportationTransporation; Scenario Analysis

\section{INTRODUCTION}

The government has paid great attention to air pollution, and clearly required that carbon dioxide emission intensity should at least drop 3.1\%. Petroleum, as the consumption energy, has become one of the major resources in carbon emission and attached much importance in carbon emission research and reduction in the tendency of low carbon economy. For this reason, considering petroleum supply chain from the perspective of carbon is obviously more and more urgent and meaningful.

Foreign countries began to notice the petroleum supply chain research in 1990s: Escudero etc. studied oil company's transportation problem and built a linear model[1]. Dempser etc. came up with a stochastic model for oil company's production problem[2]. However, it was only aimed at one link in oil supply chain, not included the whole supply chain. Neiro etc. constructed one corresponding non-linear model and analyzed the examples from the perspective of supply chain[3]. A stochastic model was directed against at uncertainty problems in reality by Alothman etc., under the condition of uncertain requirements and price to make a plan for oil production[4].

For domestic researches in this field, Li Chengbiao expounded the supply chain from the qualitative analys is angle for the first time[5]. Zhang Junling established a planning model from the supply chain angle, made a research for supply, requirement and stock, and pointed the existing problem [6]. Based on this, Wang Hua further analyzed integral solution project, however, it is mainly qualitative description, lacking relevant specification model[7].

Han Lihong explored green petroleum supply chain[8], then Sundarakani etc. took carbon emission into account,which was based on the whole supply chain, and gave new contents about supply chain from the perspective of carbon emissions [9]. Li Li studied the impact of carbon emission costs on getting excessive profits in petroleum supply chain, and analyzing by combining with Shapley game model[10]. From the perspective of carbon emissions, Luo Cheng studied the optimal combination of modes of transport.[11]. Guan Gaofeng, etc made research about the optimization petroleum supply chain, it was based on carbon trading and carbon taxes [12]. However, the study was confined to qualitative analys is, lacking of models to be built, meanwhile in the actual situation, petroleum supply chain organization will have to face the uncertainty of imported crude oil price, but is not involved in literature information.

On the basis of the above documentation, innovations of this paper are as follows: Firstly, considering the petroleum supply chain in terms of location, choice of transport modes, production planning arrangements, Secondly, for all the links of the supply chain from oil Carbon perspective for analysis. Thirdly, the crude oil supply points are divided into two categories, due to fluctuations in the price of crude oil properties. One is domestic crude oilfield production, the price is relatively stable, the other type of crude oil is imported from abroad, which price is fluctuant, Finally, the paper makes the model and study from the perspective of carbon tax policy, the result shows that, with the increasing carbon taxes, petroleum supply chain organizations tend to choose pipeline transport and imported crude oil, because it can effectively reduce carbon emission throughout the supply chain.

\section{PROBLEM DESCRIPTION}

The main objective of this paper is to build a model that could help the design and management of petroleum supply chain. When taking carbon emission and 
uncertainties into account, this paper analyzes the impact of carbon factor on supply chain. Researchers propose an extension of the two-stage stochastic programming model in order to capture the tradeoffs that between location and transportation costs, the tradeoffs that exist between cost and emission in the supply chain, and the uncertain nature of crude oil price. The model researchers propose to identify locations for refinery and select one or a combination of transportation modes for delivering crude oil and processed oil, meanwhile identify which type of crude oil researchers will select between the domestic crude oil and imported crude oil.

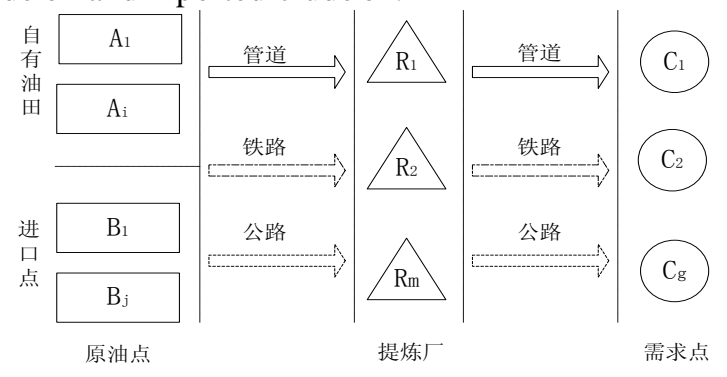

Figure 1. Petroleum Supply Chain

Fig. 1 presents the structure of the petroleum supply chain:it is consisted of crude oil spot, refineries, customers. Crude petroleum supply chain from the upstream transport to the refinery refining process then shipped the processed oil products to demanding point. Based on the characteristics of the crude oil price, crude oil spot researchers put into two categories-A and $\mathrm{B}$. The set of nodes A represent the domestic crude oilfield point such as Daqing and Shengli. The set of nodes B represent the imported crude oil point. Researchers use different arcs to represent the fact that three different modes of transportation could be used to ship: pipeline, train, truck. The cost about different modes of transport is different [13]. For rail transport, the trans portation cost is composed of two parts: fixed costs (such as the need to pay insurance cost, administrative cost, etc.) and the other part is the variable cost, associated with distance and volume. For truck transportation cost, contained only variable cost, there is no corresponding fixed cost. For pipeline transport, it is different, if researchers want to use pipeline, researchers should construct it.

With the consideration of carbon emission, researchers formulate the programming model, consisting of refinery location decision, transportation modes decision, crude oil point decision., refinery location decision. Pipeline establishment decision is a long-term decision, made prior to realization of supply chain. These are the first decision in the model, which defines the structure of the supply chain. Once these decisions are made, then the operational decisions related to the quantity of oil production and transportation. The formulation of model should take the uncertainty of imported crude oil price into account.

\section{MODEL FORMULATION}

With the national attention on carbon emission, the petroleum organization needs to consider the impact of carbon policies. These carbon policies included carbon tax policy, carbon cap policy, and carbon trading policy [14].
This paper adopted the carbon tax policy to build the model.

In the petroleum supply chain, the objective function attempts to optimize the petroleum organization by minimizing the total production and logistics costs as well as carbon emission cost and maximizing sale revenues. The two-stage stochastic programming mode researchers present below information based on scenery analysis. Each price of imported crude oil can be described as one scenery, which is denoted by w. For simplicity, researchers assume that each scenery has the same probability of occurrence. There is a probability as sociated with each scenario, which is denoted by Ew. The objective totals the first stage cos ts, which is denoted by $\mathrm{Z} 1$ and expected second stage cost which is denoted by Z2. The following is the model formulation.

$$
Z_{1}=\sum_{m \in M} \psi_{m} x_{m}+\sum_{i \in I} \sum_{m \in M} P_{i, m} y_{i, m}+\sum_{j \in J} \sum_{m \in M} P_{j, m} y_{j, m}+\sum_{g \in G} \sum_{m \in M} P_{m, g} y_{m, g}
$$

$\mathrm{Z}_{1}$ comprise of the investment costs on locate refinery plants, to install pipelines between crude point and refinery, meanwhile refinery and demanding points. xm which is a binary variable that takes the values 1 if the refinery plant is located at refinery $m$, and 0 otherwise. Meanwhile $y_{i, \mathrm{~m}}$ which is binary variable that takes the values 1 if pipeline is installed between domestic crude point $i \in I$ and site $m \in M$ of refinery, and 0 otherwise. Similarly, $y_{j, m}, y_{m, g}$ are binary variable that takes the value 1 if pipeline is installed. Other parameters researchers use are $j \in J$ which is the imported crude point; $g \in G$ which is demand point; $\psi \mathrm{m}$ which is the investment cost for the refinery plant. $P_{i, \mathrm{~m}}$ which is the investment cost for establishing a pipeline between $i$ and $m$. Similarly, $P_{j, m}$ which is the investment cost for establishing a pipeline between $j$ and $m$.

$$
\begin{aligned}
Z_{2}= & \sum_{w \in W} E^{w}\left\{\sum_{i \in l}\left[\varphi H_{i}(w)+C S_{i} * S_{i}(w)+\mathrm{V}_{i}(w) * C^{t a x}\right]+\sum_{j \in J}\left[\vartheta H_{j}(w)+C S_{j} * S_{j}(w)\right]+\right. \\
& \sum_{m \in M}\left[K_{m} H_{m}(w)+C S_{m} * S_{m}(w)+\mathrm{V}_{m}(w) * C^{t a x}\right]+\sum_{i \in l} \sum_{m \in M} \sum_{f \in F} z_{i, m}^{f}(w) C F_{i, m}^{f}+ \\
& \sum_{j \in J} \sum_{m \in M} \sum_{f \in F} z_{j, m}^{f}(w) C F_{j, m}^{f}+\sum_{m \in M} \sum_{g \in G} \sum_{f \in F} z_{m, g}^{f}(w) C F_{m, g}^{f}+\sum_{f \in F} \sum_{i \in I} \sum_{m \in M} V_{f}^{i, m}(w) * C^{t a x}+ \\
& \left.\sum_{f \in F} \sum_{j \in J} \sum_{m \in M} V_{f}^{j, m}(w) * C^{t a x}+\sum_{f \in F} \sum_{m \in M} \sum_{g \in G} V_{f}^{m, g}(w) * C^{t a x}-\sum_{m \in M} \sum_{g \in G} P^{*} \mathrm{z}_{m, g}^{f}(w)\right\}
\end{aligned}
$$

$\mathrm{Z}_{2}$ comprise of the expected production cost, transportation cost, and sale revenues of oil product. As to production, it consists of proces sing cost, storage cost and carbon emission cost. In the paper, the import crude oil does not consider carbon emissions, but the domestic oil field production of crude oil considers carbon emissions.

$\mathrm{H}_{\mathrm{i}}(w)$ is denoted the quantity of crude oil at the domestic crude point $i$ under each scenario $w . H_{m}(\mathrm{w})$ is denoted the quantity of refined oil product at refinery $m$ under each scenario $w, \varphi$ is denoted the unit production cost of crude in the domestic oilfield. $\vartheta$ is denoted the unit cost of imported crude. $S_{i}(w)$ is denoted the amount of the storage at point $i$ under scenario $w \in W, C S_{i}$ which is unite cost of crude oil storage at domestic crude point $i$. $C^{\operatorname{tax}}$ means the carbon tax that petroleum organization should pay to government per unit carbon emissions. $V_{i}(w)$ is denoted the amount of carbon emission at domestic crude 
point $i \in I$ under scenario $w \in W . V_{m}(w)$ is denoted the amount of carbon emission at refinery $m \in M$ under scenario $w \in W . V_{f}^{i, m}(w)$ is denoted the amount of carbon emission if the organization selects $f$ mode of transportation between $i$ and $m$ under scenario $w \in W$. $V_{f}^{j, m}(w)$ is denoted the amount of carbon emission if the organization seleces $f$ mode of transportation between $j$ and $m$ under scenario $w \in W . V_{f}^{m, g}(w)$ is denoted the amount of carbon emission if the organization selects $f$ mode of transportation between $m$ and $g$ under scenario $w \in W . Z_{i, m}{ }^{f}(w)$ which is the a mount of transportation if the organization selects $f$ kind transportation between $i$ and refinery $m$ under scenario $w . Z_{j m}{ }^{f}(w)$ which is the amount of transportation if the organization selects the $f$ kind transportation between $j$ and refinery $m$ under scenario $w$. $Z_{m, g}{ }^{f}(w)$ which is the amount of transportation if the organization selects the $\mathrm{f}$ kind transportation between refinery $m$ and demand point $g$ under scenario $w . C F_{i, m}{ }^{f}$ is denoted the unit transportation costs when using transportation mode $f$ between $i$ and refinery $m . C F_{j, m} f$ is denoted the unit transportation costs when using transportation mode $f$ between imported crude pont $j$ and refinery $m . C F_{m, g}{ }_{f}$ is denoted the unit transportation costs when using transportation mode $f$ between refinery $m$ and demand point $g$. Other parameters researchers use are $i$ which is the domestic crude point; $j$ which is the imported crude point; $m$ which is the site of refinery; $g$ which is the demand point; $f$ which is the transportation mode. $P$ which is unite price of oil product. $z_{m, g}^{f}(w)$ is equal to sale amount of oil product. And the objective functions are as follows.

$$
\bar{Z}=\min \left\{Z_{1}+Z_{2}\right\}
$$

Subject to

$$
\begin{gathered}
S_{i, t-1}^{1}(w)+H_{i}(w)=\sum_{m \in M} \sum_{f \in F} z_{i, m}^{f}(w)+S_{i, t}^{1}(w) \\
S_{j, t-1}(w)+H_{j}(\mathrm{w})=\sum_{m \in M} \sum_{f \in F} z_{j, m}^{f}(w)+S_{j, t}(w) \\
S_{m, t-1}(w)+H_{m, t}(w)=\sum_{g \in G} \sum_{f \in F} z_{m, g, t}^{f}(w)+S_{m, t}(w) \\
\sum_{m \in M} \sum_{f \in F} z_{m, g}^{f}(w)=D_{g} \\
\lambda\left[\sum_{f \in \mathrm{F}} \sum_{i \in I} z_{i, m}^{f}(w)+\sum_{f \in \mathrm{F}} \sum_{j \in J} z_{j, m}^{f}(w)\right]=H_{m, t}(w) \\
0 \leq H_{i}(w) \leq C_{\max }^{i} \\
0 \leq H_{j}(w) \leq C_{\max }^{j} \\
0 \leq H_{m}(w) \leq C_{\max }^{m}
\end{gathered}
$$

Constraints (4) ensure that the amount of crude production and last period storage is equal to the amount of transportation shipped to refinery plant and the current storage in domestic crude point i. Constraints (5) show that the total amount of imported crude and last period storage is equal to the amount of transportation shipped to refinery plant $\mathrm{m}$ and the current storage in imported crude point $\mathrm{j}$. Constraints (6) show that the total amount of oil product and last period storage is equal to the amount of transportation shipped to demanding point $\mathrm{g}$ and the current storage at site $\mathrm{m}$ of refinery plant. Constraints (7) show that the demanding point $g$ is equal to the amount of transportation shipped to point $\mathrm{g}$. Constraints (8) show the refinery throughput at site $\mathrm{m}$ plant is equal to the conversion of crude transportation shipped to site m plant. And $\lambda$ is denoted the conversion rate of crude to refined oil product. Finally, (9)-(11) are the non-negativity constraints.

\section{CASE STUDY}

In this case, researchers select the Daqing oilfield and Shengli oilfield as the domestic crude points, Qinhuangdao port and Qingdao port as the imported crude points. Refining plant selected Jinan refineries, and Luoyang refinery. Demanding points are Zhengzhou, Beijing, and Tianjin. Price of crude oil and refined oil price are got from the futures market. Some carbon parameters refer the literature [15], the transport parameters are according to the literature [16]. In order to be simplicity, researchers set up three scenarios, and each scenario has equal probability of occurrence.

\section{A. Comparative analysis about results}

Firstly, researchers get the result without considering carbon emission cost via lingo software. Then when researchers take carbon emission cost into account, get another result of earning value and amount of carbon emission. From the table 1, researchers can find the difference.

TABLE 1 EARNING VALUE AND CARBON EMISSION

\begin{tabular}{c|c|c}
\hline & Profit (billion) & Carbon emission (ton) \\
\hline $\begin{array}{c}\text { Without considering } \\
\text { carbon cost }\end{array}$ & 419.305 & 52430 \\
$\begin{array}{c}\text { Consider carbon cost (1 } \\
\text { Yuan/kg) }\end{array}$ & 412.172 & 29140 \\
\hline
\end{tabular}

When not to consider carbon cost, the corresponding profit is greater than taking the carbon cost into account, but the carbon emission is nearly two times of that when taking the carbon cost into account from the table 1 . The reason is that petroleum organization will not care the carbon emission if they do not need to pay the carbon tax, and as a result, the amount of carbon emission is so high.

The differences among the selection of modes of transportation, the result are shown in table 2 .

TABLE 2 CHOICE OF MODES OF TRANSPORTATION

\begin{tabular}{c|c|c|c|c}
\hline & railway & truck & pipeline & refine \\
\hline Without & $\mathrm{B}_{1} \mathrm{R}_{1} 、$ & $\mathrm{~A}_{2} \mathrm{R}_{1} 、 \mathrm{R}_{1} \mathrm{C}_{2} 、$ & $\mathrm{~B}_{2} \mathrm{R}_{2}$ & $\mathrm{R}_{1}$ \\
considering carbon & $\mathrm{A}_{1} \mathrm{R}_{1} 、 \mathrm{R}_{2} \mathrm{C}_{2}$ & $\mathrm{R}_{1} \mathrm{C}_{3} 、 \mathrm{R}_{2} \mathrm{C}_{1}$ & & $\mathrm{R}_{2}$ \\
\hline Consider carbon & $/$ & $\mathrm{B}_{1} \mathrm{R}_{1} 、 \mathrm{R}_{1} \mathrm{C}_{2} 、$ & $\mathrm{~B}_{2} \mathrm{R}_{2} 、$ & $\mathrm{R}_{1} 、$ \\
cost ( yuan $/ \mathrm{kg}$ ) & & $\mathrm{R}_{1} \mathrm{C}_{3} 、 \mathrm{R}_{2} \mathrm{C}_{1} 、 \mathrm{R}_{2} \mathrm{C}_{2}$ & $\mathrm{~A}_{2} \mathrm{R}_{1} 、 \mathrm{R}_{1} \mathrm{C}_{3}$ & $\mathrm{R}_{2}$ \\
\hline
\end{tabular}

There are three lines to choose from rail transport, four lines to choose from truck transport, but only one line to select in pipeline without carbon cost consideration. However, when researchers consider the carbon cost, the number of lines to choose in railway is down to zero, and the number of pipeline increased to three. The reason should be that the carbon emission during the transport process. However, the unit carbon emissions of railway is 
more than pipeline, when the petroleum supply chain consider the cost of carbon emissions, railway is gradually replaced by pipeline.

\section{B. Petroleum Supply Chain Based on Sensitivity Analysis of Carbon Tax}

When the carbon tax changes within the range of $[0.5$, 1.6], researchers can get the different results by solving the model. According to the result, researchers draw four graphics including carbon emissions, carbon cost, profit, the mode of transportation with the variation trend of the carbon tax rate- as shown in Fig. 2 to Fig. 5.

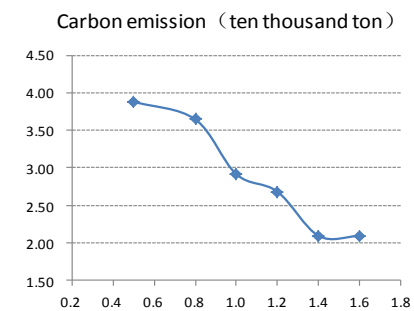

Figure 2. The changing trend of carbon emission as the carbon tax

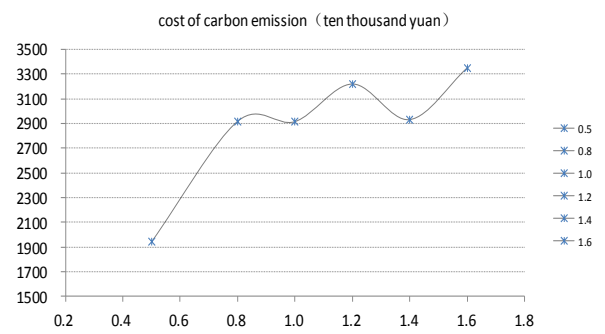

Figure 3. The changing trend of carbon emission cost as the carbon tax

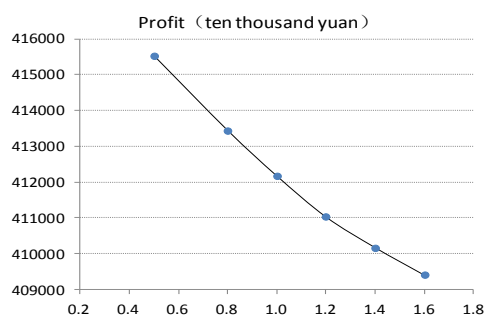

Figure 4. Profit trend along with the change of carbon tax

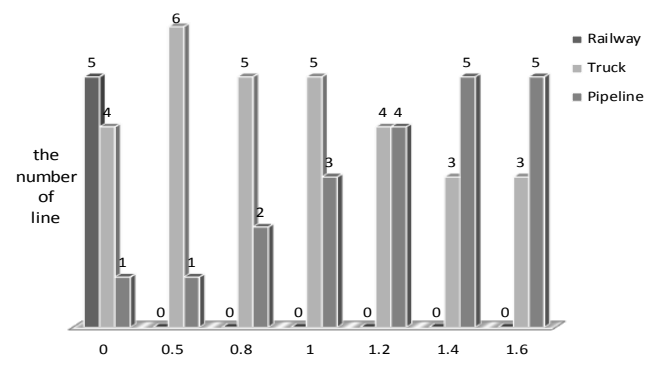

Figure 5. Transport modes selection with the change of the carbon tax

Known from Fig. 2, carbon emission shows a downward trend with the increasing of the carbon tax. When the carbon tax rate is $[0.5,1.4]$, the carbon emission decreases significantly. When carbon taxes is [1.4, 1.6], the carbon emission will no longer change. The reason may be that, the petroleum supply chain organization can adopt corresponding optimization measures, such as changing the modes of transportation has high carbon emission. For those modes have low carbon emission, in order to reduce carbon emission in the process of increasing carbon tax rate. And when it reaches the limits of 1.4, adjustment measures have been used up.

From Fig. 3, researchers can see that carbon emission cost has been increased with the improvement of carbon tax. When the carbon tax rate in the range of [0.5, 0.8], the carbon cost change is significant, and in the range of $[0.8$, 1.8 ] is relatively small change. For the volatility of the graphics, the reason may be that carbon tax and the amount of carbon emissions present opposite change. When the amplitude of the carbon tax rate is smaller than emissions decrease amplitude, the cost of carbon emission appears the increasing trend. Otherwise the cost appears the opposite trend.

From Fig. 4, researchers can see that with the improvement of carbon tax, the value of profit showing a trend of decline. In terms of overall trend, decline amplitude is more balanced. The reas on may be that with the increased carbon tax, the cost of carbon emission is getting more and more, in other word, the profit decrease.

From Fig. 5, researchers can see that with the improvement of carbon tax, preference for railway transportation mode is gradually change to pipeline.

TABLE 3 THE AMOUNT OF CRUDE SOURCE DISTRIBUTION UNDER DIFFERENT SCENARIOS (TEN THOUSAND TONS)

\begin{tabular}{|c|c|c|c|c|c|c|c|c|c|c|c|c|c|}
\hline & \multicolumn{4}{|c|}{$w=1$} & \multicolumn{4}{|c|}{$w=2$} & \multicolumn{4}{|c|}{$w=3$} \\
\hline & & & $\mathrm{A}_{2}$ & $\mathrm{~B}_{1}$ & & & $\mathrm{~A}_{2}$ & $\overline{\mathrm{B}_{1}}$ & $\mathrm{~B}_{2}$ & & $\mathrm{~A}_{2}$ & $\mathrm{~B}_{1}$ & $\mathrm{~B}_{2}$ \\
\hline \multicolumn{2}{|c|}{$\begin{array}{c}\text { Without } \\
\text { carbon tax }\end{array}$} & 6 & 100 & 80 & & 6 & 100 & 80 & & & 26 & 80 & 80 \\
\hline \begin{tabular}{l|} 
Carbon \\
\end{tabular} & 0.5 & & 100 & 6 & 80 & & 100 & 6 & 80 & & 26 & 80 & 80 \\
\hline \multirow[t]{2}{*}{$\operatorname{tax}$} & 0.8 & & 100 & 6 & 80 & & 100 & 6 & 80 & & 26 & 80 & 80 \\
\hline & 1.0 & & 100 & 6 & 80 & & 100 & 6 & 80 & & 26 & 80 & 80 \\
\hline \multirow{2}{*}{ (Yuan $/ \mathrm{kg}$} & 1.2 & & 100 & 6 & 80 & & 100 & 6 & 80 & & 26 & 80 & 80 \\
\hline & 1.4 & & 26 & 80 & 80 & & 100 & 6 & 80 & & 26 & 80 & 80 \\
\hline ) & 1.6 & & 26 & 80 & 80 & & 100 & 6 & 80 & & 26 & 80 & 80 \\
\hline
\end{tabular}

A is denoted as the domestic crude oilfield, B is denoted the imported crude point. Three scenarios represent that the imported crude price is equal to the average price, higher than the average price, and lower than the average price. From table 4 researchers can see that with the increasing of carbon tax, whether the price of imported crude is higher or lower than the average petroleum supply chain, organization tending to choose imported crude point, due to the domestic crude oilfield produce large amounts of carbon emissions in the process of production.

\section{CONCLUSIONS}

Based on the energy industry, especially carbon emission of the oil industry is more serious, and the government has increased the environmental management, this paper study the petroleum supply chain from the perspective of carbon. Through the analys is of experiment, researchers can get the following results:

With the consideration of carbon factor in petroleum supply chain, can reduce carbon emissions effectively. At 
the same time, the profit of supply chain decreased gradually with the improvement of carbon tax. The degree of incline about profit is less than carbon emission, so petroleum supply chain can take measures to reduce carbon emission greatly within the scope of profit small amplitude changes.

If takes the carbon cost into account in supply chain, the choice of modes of transportation will be different. When not considering carbon factor, the petroleum supply chain will give preference to railway transportation, due to its convenience and cheap. Once with the carbon factor consideration, the supply chain organization will choose to pipeline because of the lower carbon emission than railway transportation.

On the production plan, the carbon emission of domestic oilfield far exceeds imported crude oil point during the production. when consider the factor of carbon emissions, the oil groups will tend to choose imported crude oil .And after the price of carbon taxes breakthrough a certain point, no matter how the imported crude oil price fluctuates, it can't influence the supply chain group prefers imported crude oil

\section{REFERENCES}

[1] Escudero L.F, Quintana F.J, Salmerón J. CORO. A modeling and an algorithmic framework for oil supply, transformation and distribution optimization under uncertaint $[\mathrm{J}]$. European Journal of Operational Research, 1999, 114(3): 638--656.

[2] Dempster M.A.H, Pedron N.H, Medova E.A, et al. Planning logistics operations in the oil industry[J]. Journal of the Operational Research Society, 2000,51: 1271--1288.

[3] Neiro S.M.S, Pinto J.M. A general modeling frame work for the operational planning of petroleum supply chains[J]. Computers \& Chemical Engineering, 2004, 28(6): 871--896.

[4] Al-Othman W.B.E, Lababidi H.M.S, Alatiqi I.M, et al. Supply chain optimization of petroleum organization under uncertainty in market demands and prices[J]. European Journal of Operational Research, 2008, 189(3): 822--840.
[5] LI Cheng-biao, WU Xian-jing. Study on supply chain management of petroleum industry.Logistics Technology,2004,(1):52--54.

[6] Zhang Junling. Research on optimizaiton of prtroleum supply chain based on planning model[D]. Anhui:Hefei University of Technology,2009.

[7] Wang Hua.. Integrated Optimization Program of Supply Chain from Crude Oil to Products [J]. Petroleum Planning \& Engineering,2010,21(2):1--5.

[8] Han Lihong, Zeng Jinfang. Green Supply Chain Management to Explore the Oil Industry. Resources [J]. Industrial Economy, 2007, 11:17-21.

[9] Sundarakani B, De Souza R, Goh M, et al. Modeling carbon footprints across the supply chain[J].International Journal of Production Economics, 2010, 128(1): 43-50.

[10] LI Li,XUE Dong-hui, LIU Jian. The Influence of Carbon Emission Cost to Getting Excess Profit by Chinese Oil Supply Chain Based on Shapley Game Model[J]. Supply Chain Management, 2011, 1: 36-40.

[11] Luo Cheng. Study on the Combination Optimization Model of Multiple Transportation Modes Considering the Carbon Emission Control [J]. Journal of Shaanxi University of Science \& Technology, 2011,29: 113-116.

[12] Gun Gaofeng,Dong Qianli. Research on the optimization of low carbon petroleum supply chain transportation network under the perspective of carbon trading and carbon tax $[\mathrm{J}]$. Technological Development of Enterprise,2014,33(1):51--53.

[13] Marufuzzaman M, Eksioglu S.D, Mondala A.A techno economic analysis of pipelining wastewater sludge transportation $[\mathrm{C}] / /$ Proceedings of the industrial and systems engineering research conference (ISERC). Orlando, Fl, USA. 2012: 19--23.

[14] Benjaafar S, Li Y, Daskin M. Carbon footprint and the management of supply chains: Insights from simple models[J]. Automation Science and Engineering, IEEE Transactions on, 2013, 10(1): 99--116.

[15] Jin Lingqin. Model and Algorithm Study on Intermodal Transpiration Path Optimization on the Carbon Tax Mechanism[D]. Liao Ning: Northeastern University, 2012.

[16] Marufuzzaman M, Ekşioğlu S.D, Hernandez R. Truck versus Pipeline Transportation Cost Analysis of Wastewater Sludge [J]. Transportation Research Part A: Policy and Practice, 2015, 74: 1430 . 